\title{
Erratum: Argonaute 2 promotes angiogenesis via the PTEN/VEGF signaling pathway in human hepatocellular carcinoma
}

Zhen-long YE\#, Yao HUANG\#, Lin-fang LI, Hai-li ZHU, Hai-xia GAO, Hui LIU, Sai-qun LV, Zeng-hui XU, Luo-ning ZHENG, Tao LIU, Jing-lei ZHANG, Hua-jun JIN, Qi-jun QIAN

Acta Pharmacol Sin 2015; 36: 1237-45.

\# The first two authors Zhen-long YE and Yao HUANG contributed equally to this work.

The editors are sorry for missing the indication of the co-first authors.

Acta Pharmacologica Sinica (2018) 39: 329; doi: 10.1038/aps.2018.3 